\title{
Studying of the Status of Quality of Life and its Predictors in Adult Asthmatic Patients in Ahvaz: Basic Information for Better Control of
} Asthma

\author{
Marzieh Shayesteh Fard, ${ }^{1}$ Mojtaba Miladinia, ${ }^{2}$ Hojjat Zareh Houshyari Khah,, ${ }^{3,}$ Seyed Hamid Borsi, ${ }^{4}$ \\ and Kourosh Zarea ${ }^{2}$ \\ ${ }^{1}$ Student Research Committee, Shiraz University of Medical Sciences, Shiraz, IR Iran \\ ${ }^{2}$ Nursing Care Research Center in Chronic Diseases, School of Nursing and Midwifery, Ahvaz Jundishapur University of Medical Sciences, Ahvaz, IR Iran \\ ${ }^{3}$ Abadan Faculty of Nursing, Abadan University of Medical Sciences, Abadan, IR Iran \\ ${ }^{4}$ Ahvaz Jundishapur University of Medical Sciences, Ahvaz, IR Iran \\ "Corresponding author: Hojjat Zareh Houshyari Khah, Abadan Faculty of Nursing, Abadan University of Medical Sciences, Abadan, IR Iran. Tel: +98-6313335363, E-mail: \\ hoshyari@ajums.ac.ir
}

Received 2016 April 22; Revised 2016 May 16; Accepted 2016 July 12.

\begin{abstract}
Background: Asthma is a chronic obstructive pulmonary disease, which can affect the patients' quality of life (QoL). Nowadays, evaluating QoL and its predictors is considered a criterion for the assessment of appropriate control and cure for asthma and other chronic diseases. Knowing how well patients feel and what aspects of QoL they have no feelings for, would help make future plans in a way that their pain will be lessened.

Objectives: The primary objective of the current study was to investigate the OoL among adult patients with asthma in Ahvaz, Iran in during years 2014 and 2015. The secondary objective was to determine the most powerful predictors for QoL among such patients. Methods: In this cross-sectional study, by using the convenience sampling method, 384 patients were selected with respect to the inclusion criteria. The data collection tools fell into two parts, the first of which included demographic variables and the second part was a Mini asthma quality of life questionnaire. The data were collected by an interviewer, who interviewed patients before being visited by the specialist at the clinic.

Results: All in all, the lowest mean QoL was obtained for emotional functions dimension. According to the findings, the majority of patients had an undesirable $\operatorname{OoL}(43.8 \%)$. Finally, the results indicated that the duration of disease was the most powerful predictor of QoL among asthmatic patients $(\beta=-0.76, \mathrm{P}=0.001)$.

Conclusions: The study results indicated that adult patients with asthma did not have a desirable OoL, a fact which requires making serious plans to control the disease better and to improve the OoL. Considering the fact that the duration of disease was the most powerful predictor of OoL among asthmatic patients, it is essential for the medical team to pay special attention to the patients suffering from asthma for a longer duration.
\end{abstract}

Keywords: Asthma, Quality of Life, Predictor

\section{Background}

Asthma is a chronic obstructive pulmonary disease and a disorder of the airways. It is characterized by a reversible spasm in the bronchi (1). Currently, asthma is one of the most prevalent chronic diseases, with almost 300 million people affected by this disease around the world while it is increasingly spreading all over the world and Iran (2). Every year, this disease imposes high economic and healthcare costs on societies, where 20 million hospital admissions, being hospitalized for almost five days on average, are annually reported due to asthma (3). Moreover, about 15 million people are affected by inability and disability because of asthma, and 255,000 people die from it every year. It is predicted that the mortality rate will in- crease by $20 \%$ during the next ten years (4).

Given the complications of asthma, the main objectives of health communities are to control and cure it properly. Therefore, therapeutic measures should be taken in order to control this disease in the best way possible because poor asthma control would have irreversible effects on patients and their families, increase admissions to hospitals and emergency centers, limit activities, result in nighttime awakenings and absenteeism from work or school, and impose high costs on the healthcare system (5, 6). Unfortunately, evidence indicates that although there are appropriate standards for controlling asthma, many patients are affected by unfavorable controls and recurrence of attacks. However, the expenditures of patients 
having recurrent attacks come to something more than three times the expenditures of patients, who do not experience such attacks (7). Nowadays, evaluating quality of life (OoL) is considered a criterion for the assessment of appropriate control and cure for asthma and other chronic diseases (8-10).

People with asthma experience particularly intermittent attacks characterized by no symptoms in long periods in some cases. The exacerbation of attacks can influence daily work, school, recreations, social activities, and other affaires, which may have negative impacts on the quality of patients' life $(3,4)$. Asthmatic patients qualities of life is usually investigated in four areas including activity limitation, symptoms, emotional functions and environmental stimuli (3). Knowing how fine patients feel and what aspects they have no feelings for, would help make future plans in a way that their pains will be lessened; therefore, the disease will be controlled better $(9,11)$. Moreover, information pertaining to the predictors of the OoL can help improve it (12).

A literature review indicated that the QoL and relevant predictors have been investigated among children with asthma, and there are few studies on adult asthmatic patients (13-15). Therefore, given the high prevalence of asthma in Khuzestan province and Ahvaz city, bad and polluted weather of this region in the recent years and its undeniable impact on asthmatic patient, and no investigation that has addressed about this subject in Khuzestan province, it was decided to conduct a study to investigate the OoL and its predictors among adult patients with asthma. Thus, the results can be used to study the available treatment outcome and apply a more effective healthcare plan in the future.

\section{Objectives}

The primary objective of the current study was to investigate OoL among adult patients with asthma in Ahvaz, Iran during years 2014 and 2015. The secondary objective was to determine the most powerful predictors for OoL among such patients.

\section{Methods}

\subsection{Study Design and Population}

This cross-sectional study was performed on 384 patients with asthma referred to a specific clinic of asthma, an Allery of Imam-Khomeini hospital affiliated to Ahvaz Jundishapur University of Medical Sciences of Iran, during years 2014 and 2015. The following formula was used to estimate the size of sample with a power of $80 \%, d=0.06$ and a significance level of $0.05\left(n=z^{2}{ }_{1-\alpha / 2} \times p(1-p) / d^{2}\right)$. Using the convenience sampling method, 384 patients were selected with respect to the inclusion criteria, which were as follows: 1) a definitive diagnosis by a specialist; 2 ) age ranging from 18 to $70 ; 3$ ) at least a six-month history of asthma; 4) a minimum period of four months being treated with corticosteroids; and 5) no critical conditions at the time of answering the questions. In additions, exclusion criteria were as follow: 1) being pregnant; 2) having experienced chronic respiratory failure, heart failure, cancer and etc.; 3) having psychological disorders.

\subsection{Measurement Method}

The data collection tools fell into two parts, the first of which included the demographics having 12 items. The second part was the mini asthma OoL questionnaire including 15 items classified under four areas such as activity limitation (four items), symptoms (five items), and emotional function (three items) and environmental stimuli (three items). Based on the seven-degree Likert scale, each aspect was scored from one to seven (the highest disorder $=1$; the lowest disorder $=7$ ). A higher score indicated a better OoL. It took three to four minutes to complete this questionnaire (16). After conducting a pilot study on 30 individuals of the research units and using the internal consistency method, the reliability of the questionnaire was calculated through Cronbach's alpha coefficient (0.81). The data were collected by a nurse having interviews with patients before being visited by the specialist at the clinic.

\subsection{Data Analysis}

Descriptive statistics were used for data analysis including mean and standard deviation for continuous variables (age, length of disease and OoL dimensions) and frequency and percentage for categorical variables (gender, residence, level of education and marital status). Also, Linear regression test was used to determine predictors of OoL. In this study, SPSS version 16 was used for data analysis. P value $<0.05$ was considered statistically significant.

\subsection{Ethical Considerations}

Ethical considerations were taken into account with respect to the declaration of Helsinki (DoH). This study was confirmed by the ethics committee at Ahvaz Jundishapur University of Medical Sciences. Before conducting the study, the research objectives were explained to the participants, all of whom gave written consents in order to participate in the study. 


\section{Results}

The results indicated that the majority of participants were married (83.9\%), urban (86\%), and non-smoking (85.7\%) and had a diploma (27.5\%). Table 1 indicates the demographics and information pertaining to the patients.

\begin{tabular}{|c|c|}
\hline Variables & Values $^{\mathrm{a}}$ \\
\hline Age & $46.38 \pm 17.51$ \\
\hline \multicolumn{2}{|l|}{ Gender } \\
\hline Male & $195(50.6)$ \\
\hline Female & $190(49.4)$ \\
\hline \multicolumn{2}{|l|}{ Marital Status } \\
\hline Married & $323(83.9)$ \\
\hline Single & $62(16.1)$ \\
\hline \multicolumn{2}{|l|}{ Smoking Record } \\
\hline No & $330(85.7)$ \\
\hline Yes & $55(14.3)$ \\
\hline Duration of Disease, $y$ & $6.4 \pm 7.547$ \\
\hline \multicolumn{2}{|l|}{ Education } \\
\hline Illiterate & $144(37.4)$ \\
\hline High School & $93(24.2)$ \\
\hline Diploma & $106(27.5)$ \\
\hline Academic & $42(10.9)$ \\
\hline \multicolumn{2}{|l|}{ Residence } \\
\hline Urban & $331(86)$ \\
\hline Rural & $54(14)$ \\
\hline
\end{tabular}

${ }^{\mathrm{a}}$ Values are expressed as mean (SD) or No. (\%).

Table 2 shows different aspects of OoL. The research results, pertaining to asthmatic patients' OoL, indicated that the majority of patients had an appropriate OoL with regards to activity limitation (39\%). Regarding symptoms (47.5\%) and emotional functions (51.2\%), the majority of patients had a relative QoL. Finally, the majority of patients reported an undesirable QoL with respect to environmental stimuli (45.7\%). All in all, the lowest mean was obtained for emotional functions. According to the findings, the majority of patients had an undesirable QoL (43.8\%) (Table 2).

Table 3 indicates the predictors of QoL. According to the results of this study, age, education, and the duration of disease were significant predictors of QoL. They could actually predict the QoL. However, gender, marital status, and place of residence were significant predictors of life. Finally, the results indicated that the duration of disease
Table 2. The Frequency Distribution of Scores in Different Dimensions of Patients' Quality of Life

\begin{tabular}{|c|c|}
\hline Dimensions of Quality of Life & No. (\%) \\
\hline \multicolumn{2}{|l|}{ Activity Limitation } \\
\hline Undesirable & $93(24.2)$ \\
\hline Relatively Desirable & $142(36.9)$ \\
\hline Desirable & $150(39)$ \\
\hline \multicolumn{2}{|l|}{ Symptoms } \\
\hline Undesirable & $127(33)$ \\
\hline Relatively Desirable & $183(47.5)$ \\
\hline Desirable & $75(19.5)$ \\
\hline \multicolumn{2}{|l|}{ Emotional Functions } \\
\hline Undesirable & $157(40.8)$ \\
\hline Relatively Desirable & $197(51.2)$ \\
\hline Desirable & $31(8.1)$ \\
\hline \multicolumn{2}{|l|}{ Environmental Stimuli } \\
\hline Undesirable & $176(45.7)$ \\
\hline Relatively Desirable & $165(42.9)$ \\
\hline Desirable & $44(11.4)$ \\
\hline \multicolumn{2}{|l|}{ Total Quality of Life } \\
\hline Undesirable & $180(11.4)$ \\
\hline Relatively Desirable & $105(27.3)$ \\
\hline Desirable & $100(26)$ \\
\hline
\end{tabular}

was the most powerful predictor of QoL among asthmatic patients $(\beta=-0.76, \mathrm{P}=0.001)$

Table 3. Predictors of Ouality of Life, With $95 \%$ Confidence Interval ${ }^{\mathrm{a}, \mathrm{b}}$

\begin{tabular}{lcc}
\hline Variables & Standardized Coefficient (Beta) & P Value \\
\hline Age & -0.57 & $0.007^{\mathrm{c}}$ \\
Gender & 0.025 & 0.851 \\
\hline Level of education & 0.34 & $0.031^{\mathrm{c}}$ \\
\hline Marital status & 0.087 & 0.656 \\
\hline Residence & -0.11 & 0.331 \\
\hline Length of disease & -0.76 & $0.001^{\mathrm{c}}$ \\
\hline
\end{tabular}

${ }^{\mathrm{a}}$ Data are presented as standardized coefficient (Beta) and P value.

${ }^{\mathrm{b}}$ Liner regression was used.

${ }^{\mathrm{c}}$ Significant difference (P value $\left.<0.05\right)$.

\section{Discussion}

The research findings suggest that $46.8 \%$ of asthmatic people reported an undesirable QoL. However, only 26\% of 
patients said that they had a desirable QoL. Asthmatic patients' QoL, known as a clinical evaluation tool, reflects the impact of disease on the life of patients (17). Based on the results of the current study, it can therefore be stated that almost half of the patients believed that asthma had major impacts on different aspects of their lives. Having poorer health conditions, they were worried about asthma. It is implied that there are still flaws pertaining to healthcare services for asthma and appropriate control of the diseases in our healthcare system, and basic interventions should be done in this regard. Given the increasing spread of asthma in Iran and also the increasing expenditures for treatment and patients' lost workdays influencing their daily activities, the QoL bears a special importance among such patients (18).

It is worth mentioning that $45.7 \%$ of participants reported an undesirable QoL regarding environmental stimuli, which are among the factors influencing the QoL and asthma control. In fact, they include limitations imposed on patients due to environmental stimuli such as dust, cigarette smoke and air pollution. Such stimuli can have considerable impacts on the pathogenicity of asthma and the QoL as a result. Clinical observations have also confirmed the fact that a part of patients' concerns about asthma is concentrated on environmental stimuli (19). The current results are consistent with the reality throughout Khuzestan province. Recurrent phenomena of dust and dirt on one hand, and air-polluting centers on the other hand in recent years have increased the amount of asthmatic environmental stimuli. Therefore, the recurrence of asthmatic attacks and pathogenicity has increased. The findings of previous studies conducted by Adams et al. Amponet al. Ford et al. and Siroux et al. (20-23) were similar to the current research findings. In those studies, the majority of subjects reported an undesirable OoL; however, people had a desirable OoL in other studies $(24,25)$. This difference can be explained by different geographical factors or even various healthcare systems. Thus, more efforts should be made to provide comprehensive healthcare for the appropriate control of asthma in our healthcare system.

The results of this study also indicated that the duration of disease and age were the most powerful predictors of QoL among adult patients with asthma. The duration of disease had an inverse relationship with QoL. In other words, if the duration increases, quality is reduced. Therefore, patients who have been affected for a long time should receive greater attention. Age is also inversely related with the QoL. In other words, the QoL decreases as the patient ages. Thus, older patients should receive more care.

Also, this study had some limitations: 1) patients were enrolled from only one health center; and 2) this investiga- tion was conducted in one city of Iran. Therefore, the generalizability of the study findings is limited.

\subsection{Conclusion}

The research results indicated that adult patients with asthma did not have a desirable QoL, a fact, which requires making serious plans in different areas such as healthcare, treatment, familial supports, and social supports to control the disease better and to improve QoL. Nowadays QoL is considered a criterion for the evaluation of asthma control. Given the fact that the results of this study indicated that the lowest mean QoL was for emotional functions, it is suggested for serious corrective actions and plans to be organized in this regard. Considering the fact that the duration of disease was the most powerful predictor of QoL among asthmatic patients, it is essential for the medical team to pay special attention to the patients suffering from asthma for a longer time. Therefore, it is essential to improve the QoL.

\subsection{Implications for Practice}

Medical teams, including nurses and doctors, can use the results of this study to make appropriate plans for the future and improve healthcare measures based on fundamental evidence. Therefore, asthmatic patients' qualities of life can be increased so that they suffer less. It is suggested for future studies to investigate other predictors of QoL among asthmatic patients and the methods of improving QoL.

\section{Acknowledgments}

The investigators would like to thank all the patients for participated in this study.

\section{Footnotes}

Authors' Contribution: Marzieh Shayesteh Fard: study concept and design, interpretation of data, drafting the manuscript, and critical revision for important intellectual content; Hojjat Zareh Houshyari Khah and Seyed Hamid Borsi: study conception and design, supervision and analysis; Mojtaba Miladinia and Kourosh Zarea: acquisition of data, drafting the manuscript, and critical revision for important intellectual content.

Funding/Support: This investigation was a research project (No u-8717), which was funded by the research center of Ahvaz Jundishapur University of Medical Sciences. 


\section{References}

1. Bush A, Fleming L. Diagnosis and management of asthma in children. BMJ. 2015;350:h996.

2. Behera D, Sehgal IS. Bronchial asthma-Issues for the developing world. Indian J Med Res. 2015;141(4):380-2. doi: 10.4103/09715916.159237. [PubMed: 26112836].

3. Ross JA, Yang Y, Song PX, Clark NM, Baptist AP. Quality of life, health care utilization, and control in older adults with asthma. J Allergy Clin Immunol Pract. 2013;1(2):157-62. doi: 10.1016/j.jaip.2012.12.003. [PubMed: 24565454].

4. Alpaydin AO, Bora M, Yorgancioglu A, Coskun AS, Celik P. Asthma control test and asthma quality of life questionnaire association in adults. Iran J Allergy Asthma Immunol. 2012;11(4):301-7. [PubMed: 23264406].

5. Braido F, Baiardini I, Balestracci S, Ghiglione V, Stagi E, Ridolo E, et al. Does asthma control correlate with quality of life related to upper and lower airways? A real life study. Allergy. 2009;64(6):937-43. doi: 10.1111/j.1398-9995.2008.01932.x. [PubMed: 19243359].

6. Buist AS, Vollmer WM, Wilson SR, Frazier EA, Hayward AD. A randomized clinical trial of peak flow versus symptom monitoring in older adults with asthma. Am J Respir Crit Care Med. 2006;174(10):1077-87. doi: 10.1164/rccm.200510-16060C. [PubMed:16931634].

7. Haughney J, Price D, Kaplan A, Chrystyn H, Horne R, May N, et al. Achieving asthma control in practice: understanding the reasons for poor control. Respir Med. 2008;102(12):1681-93. doi: 10.1016/j.rmed.2008.08.003. [PubMed: 18815019].

8. Lane S, Molina J, Plusa T. An international observational prospective study to determine the cost of asthma exacerbations (COAX). Respir Med. 2006;100(3):434-50. doi: 10.1016/j.rmed.2005.06.012. [PubMed: 16099149].

9. Miladinia M, Baraz S, Shariati A, Malehi A, Amadzadeh A. Relationship Between Chronic Pain and Quality of Life in Patients With Acute Leukemia Undergoing Chemotherapy. Jundishapur J Chron Dis Care. 2015;4(3).

10. Baraz S, Shahbazian HB, Miladinia M, Zarea K. Video Training Programs and the Quality of Life of Patients With Type II Diabetes. Jundishapur J Chron Dis Care. 2015;4(4).

11. Jones PW. Interpreting thresholds for a clinically significant change in health status in asthma and COPD. Eur RespirJ. 2002;19(3):398-404. [PubMed: 11936514].

12. Baraz S, Miladinia M, Mosavinouri E. A Comparison of Quality of Life between Adolescences with Beta Thalassemia Major and their Healthy Peers. Int J Pediatr. 2016;4(1):1195-204.
13. Annett RD, Bender BG, Lapidus J, Duhamel TR, Lincoln A. Predicting children's quality of life in an asthma clinical trial: what do children's reports tell us?. J Pediatr. 2001;139(6):854-61. doi: 10.1067/mpd.2001.119444. [PubMed: 11743513].

14. Moy ML, Israel E, Weiss ST, Juniper EF, Dube L, Drazen JM, et al. Clinical predictors of health-related quality of life depend on asthma severity. Am J Respir Crit Care Med. 2001;163(4):924-9. doi: 10.1164/ajrccm.163.4.2008014. [PubMed: 11282767].

15. Perosa GB, Amato IA, Rugolo LMSS, Ferrari GF, Oliveira MCF. Quality of life of children and adolescents with asthma: its relationship to maternal coping strategies. Revista Paulista de Pediatri. 2013;31:145-51.

16. Juniper EF, Guyatt GH, Cox FM, Ferrie PJ, King DR. Development and validation of the Mini Asthma Quality of Life Questionnaire. Eur Respir J. 1999;14(1):32-8. [PubMed:10489826].

17. Archea C, Yen IH, Chen H, Eisner MD, Katz PP, Masharani U, et al. Negative life events and quality of life in adults with asthma. Thorax. 2007;62(2):139-46. doi: 10.1136/thx.2006.065730. [PubMed: 16928721].

18. Pedram Razi SH, Bassampour SH, Kazemnejad A. Quality of Life in Asthmatic Patients. J Hayat. 2007;13(1):29-34.

19. Matheson M, Raven J, Woods RK, Thien F, Walters EH, Abramson M. Wheeze not current asthma affects quality of life in young adults with asthma. Thorax. 2002;57(2):165-7. [PubMed: 11828048].

20. Adams RJ, Wilson DH, Appleton S, Taylor A, Dal Grande E, Chittleborough CR, et al. Underdiagnosed asthma in South Australia. Thorax. 2003;58(10):846-50. [PubMed: 14514934].

21. Ampon RD, Williamson M, Correll PK, Marks GB. Impact of asthma on self-reported health status and quality of life: a population based study of Australians aged 18-64. Thorax. 2005;60(9):735-9. doi: 10.1136/thx.2005.040311. [PubMed: 16135680].

22. Ford ES, Mannino DM, Homa DM, Gwynn C, Redd SC, Moriarty DG, et al. Self-reported asthma and health-related quality of life: findings from the behavioral risk factor surveillance system. Chest. 2003;123(1):119-27. [PubMed: 12527612].

23. Siroux V, Boudier A, Anto JM, Cazzoletti L, Accordini S, Alonso J, et al. Quality-of-life and asthma-severity in general population asthmatics: results of the ECRHS II study. Allergy. 2008;63(5):547-54. doi: 10.1111/j.1398-9995.2008.01638.x. [PubMed: 18394129].

24. Axelsson M, Emilsson M, Brink E, Lundgren J, Toren K, Lotvall J. Personality, adherence, asthma control and health-related quality of life in young adult asthmatics. Respir Med. 2009;103(7):1033-40. doi: 10.1016/j.rmed.2009.01.013. [PubMed: 19217764].

25. Hasselgren M, Gustafsson D, Stallberg B, Lisspers K, Johansson G. Management, asthma control and quality of life in Swedish adolescents with asthma. Acta Paediatr. 2005;94(6):682-8. doi: 10.1080/08035250510025851. [PubMed: 16188769]. 